\title{
Associations between personality changes and nucleus accumbens ablation in opioid addicts
}

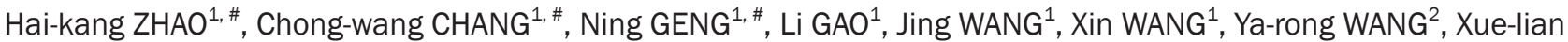 \\ WANG $^{1, *}$, Guo-dong $\mathrm{GAO}^{1,}$ * \\ ${ }^{1}$ Department of Neurosurgery, Tangdu Hospital, the Fourth Military Medical University, Xi'an 710038, China; ${ }^{2}$ Department of Radiology, \\ Tangdu Hospital, the Fourth Military Medical University, Xi'an 710038, China
}

\begin{abstract}
Aim: It has been reported that nucleus accumbens (NAc) lesions can help to prevent relapse in opioid addicts. This article aimed to investigate associations between personality changes and NAc lesions.

Methods: The surgery group consisted of 78 patients who had received bilateral stereotactic lesions of the NAc to treat opioid addiction. Seventy two non-surgery opioid addicts were appropriately paired with the patients of the surgery group as the non-surgery group. All participants were interviewed in person and received urine tests, naloxone provocative tests and hair tests to determine the prevalence of relapse. Eysenck personality questionnaire (EPQ) and the health survey questionnaire (SF-36) were employed to assess personality and functional health, respectively.

Results: In the surgery group, 30 participants relapsed, and the non-relapse rate was $61.5 \%$ (48/78). Compared with the Chinese normative data, the neuroticism $(\mathrm{N})$ and psychoticism $(\mathrm{P})$ dimensions of the EPQ in the non-surgery group were significantly higher, whereas the lie $(L)$ dimension was significantly lower. There was no significant difference in all dimensions of the EPQ between the surgery group and the Chinese normative data. The $\mathrm{N}$ dimension in the relapse group and the $\mathrm{L}$ dimension in the surgery group were significantly lower than those of the non-surgery group. The P dimension in the relapse group was significantly higher than that of the non-relapse group. The extraversion (E) dimension was relatively stable between these groups.

Conclusion: Although the influence of other factors cannot be excluded, it is apparent that surgically induced NAc lesions are associated with lower $\mathrm{P}$ and $\mathrm{N}$ dimensions for opioid addicts, and a higher $\mathrm{P}$ dimension is associated with a tendency to relapse.
\end{abstract}

Keywords: opiate addiction; relapse; nucleus accumbens lesion; Eysenck personality questionnaire; health survey questionnaire (SF-36); long-term follow-up study

Acta Pharmacologica Sinica (2012) 33: 588-593; doi: 10.1038/aps.2012.10; published online 16 Apr 2012

\section{Introduction}

Addictive diseases, including opioid dependence, are a chronic and recurrent cerebropathy (National Institutes of Health, 1998), causing abnormalities in mentality and behavior $^{[1]}$. The success rate for treating opioid dependence using traditional therapy is approximately $3 \%-7 \%^{[2]}$. The treatment of opiate addiction remains one of the most challenging problems worldwide. Recently, a large number of animal and clinical studies have suggested that the nucleus accumbens (NAc) is an important part of the dopaminergic (mesocorticolimbic) pathway and plays a key role in drug addiction ${ }^{[3-6]}$.

The Research Center of Functional Cerebropathy of Tangdu

\footnotetext{
\# These authors contributed equally to this article.

* To whom correspondence should be addressed.

E-mail tdwxlian@126.com (Xue-lian WANG); gguodong@fmmu.edu.cn (Guo-dong GAO)

Received 2011-09-30 Accepted 2012-02-01
}

Hospital has been attempting to treat opioid addiction via bilateral stereotactic NAc lesions since July 2000. By November 2004, this operation had been performed on a total of 272 opiate addicts, and short-term follow-ups revealed satisfactory results ${ }^{[7,8]}$. However, this treatment was halted due to ethical problems associated with irreversible damage to the brain structure and the lack of long-term follow-up data. The current investigation aims to assess the long-term effect of the treatment on the addicts of surgically treated opioid dependence.

\section{Materials and methods Participants}

For the surgery group, 100 patients who had received bilateral stereotactic NAc lesions were randomly selected from a total of 272 patients. The non-surgery group was comprised of 72 participants who were selected from the voluntary drug 
rehabilitation institution on the basis of their match to the surgery group participants. The pairing of surgery group participants with opiate addicts who had not undergone the operation was performed according to a number of preoperative characteristics: age, gender, education level, place of birth, category of drugs taken pre- or post-operatively, duration of drug abuse, treatment history and personality disorders (Table 1). The exclusion criteria included participants who could not understand the questionnaire items correctly, could not concentrate (eg, when completing questionnaires) or failed to complete or attend the follow-up visits. All volunteers gave full consent to participate in the study.

Table 1. Basic information for the surgery group and non-surgery groups.

\begin{tabular}{|c|c|c|}
\hline Items & $\begin{array}{l}\text { Surgery group } \\
\quad(n=72)\end{array}$ & $\begin{array}{l}\text { Non-surgery group } \\
\qquad(n=72)\end{array}$ \\
\hline \multicolumn{3}{|l|}{ Age (Year) } \\
\hline $18-30$ & 25 & 25 \\
\hline $30-40$ & 34 & 34 \\
\hline $40-50$ & 11 & 11 \\
\hline $50-60$ & 2 & 2 \\
\hline$>60$ & 0 & 0 \\
\hline Male & 59 (81.9\%) & 59 (81.9\%) \\
\hline \multicolumn{3}{|l|}{ Years of education } \\
\hline$<6$ years & 17 & 17 \\
\hline $6-12$ years & 45 & 45 \\
\hline$>12$ years & 10 & 10 \\
\hline \multicolumn{3}{|l|}{ Frequent dwelling place } \\
\hline Rural area & 23 & 23 \\
\hline Town or small city & 28 & 28 \\
\hline City above provincial level & 21 & 21 \\
\hline \multicolumn{3}{|l|}{ History of drug addiction } \\
\hline 3-8 years & 52 & 52 \\
\hline $8-15$ years & 16 & 16 \\
\hline$>15$ years & 4 & 4 \\
\hline \multicolumn{3}{|l|}{ Main addictive drugs } \\
\hline Heroin & 72 & 72 \\
\hline \multicolumn{3}{|l|}{ Occasional combination drugs } \\
\hline Morphine & 4 & 4 \\
\hline Opium & 8 & 8 \\
\hline Cocaine & 5 & 5 \\
\hline \multicolumn{3}{|l|}{ Equivalent weight of heroin daily } \\
\hline$<0.5 \mathrm{~g}$ & 13 & 13 \\
\hline $0.5-1.0 \mathrm{~g}$ & 44 & 44 \\
\hline$>1.0 \mathrm{~g}$ & 15 & 15 \\
\hline \multicolumn{3}{|l|}{ Treatment history } \\
\hline Drug replacement therapy & 28 & 28 \\
\hline Nonmedicine therapy & 44 & 44 \\
\hline Personality disorder & 3 & 3 \\
\hline
\end{tabular}

Of the 100 patients in the surgery group, 10 did not fully understand the questionnaire items and 12 did not complete the study. The total number of participants in the surgery group was 78 (69 males, 9 females, average age 31.53 \pm 9.84 years). The number of years of education was $11.76 \pm 5.29$. The addictive substances taken by the surgery group were primarily of the opioid drug class. The duration of preoperative opioid addiction was $6.30 \pm 4.48$ years, and the total preoperative opioid dose was $0.54 \pm 0.67 \mathrm{~g}$ daily. The follow-up time for the surgery group ranged from 5 to 8 years post-operatively and averaged $5.92 \pm 1.33$ years. Seventy-two surgery group patients were successfully paired with the non-surgery group (the paired rate was $92 \%$ ).

The evaluators and data processing staff were blinded to each participant's surgical status. The study ran from December 1, 2009 to January 31, 2010. This study obtained the approval of the Fourth Military Medical University Ethics Committee.

\section{Measurement methods and tools}

Non-relapses were defined based on negative results in urine tests, naloxone provocative tests, hair testing and the absence of complaints from patients and family members. A positive result for these test measures was defined as a relapse. The position of lesion foci in the surgery group participants was re-examined using post-operative magnetic resonance imaging (MRI).

The investigation included personal interviews and selfassessment scales. Screening for mental diseases and personality disorders was performed by two psychiatrists in accordance with the International Classification of Diseases (ICD-10).

\section{Eysenck personality questionnaire (EPQ)}

The EPQ is comprised of scales for 4 dimensions of personality: extraversion $(\mathrm{E})$, wherein higher scores represent greater extroversion; neuroticism (or nervosity, N), wherein higher scores reflect less stable emotions; psychoticism $(\mathrm{P})$, wherein higher scores indicate higher psychoticism; and lie (L), wherein higher scores are associated with a greater tendency to lie. The EPQ Chinese Revised Edition was used to provide the normative data for this study ${ }^{[9]}$.

\section{Short form-36 health survey questionnaire (SF-36)}

The SF-36 includes 8 dimensions of functional health: physical functioning (PF), role-physical (RP), bodily pain (BP), general health $(\mathrm{GH})$, vitality (VT), social functioning (SF), role-emotional (RE) and mental health $(\mathrm{MH})$. A higher score in each of these dimensions is indicative of better health.

\section{Statistical analysis}

Descriptive statistics (mean $\pm S D$ ) were calculated for all questionnaire items. The statistical analysis was performed using SPSS 12.0 software. The statistical analyses included paired sample $t$-tests, independent sample $t$-tests, relative analysis, and the $\chi^{2}$ test. A significance level of $P<0.05$ was considered to be statistically significant.

\section{Results}

Re-examination of the ablation locus and relapse rate for the surgery group

The positions of lesion foci in the surgery patients were located 
accurately and the errors of the foci were within the normal range. MRIs taken preoperatively, 1 week postoperatively and 5 years postoperatively are shown in Figures 1 and 2 . The non-relapse rate for the surgery group was $61.5 \%(48 / 78)$.

\section{Comparison of personality (EPQ) differences}

As shown in Table 2, the $\mathrm{N}$ and $\mathrm{P}$ dimensions for the nonsurgery group were higher $(P<0.05)$, and the $\mathrm{L}$ dimension for the non-surgery group was lower $(P<0.05)$ compared with the normative data. The $\mathrm{L}$ dimension for the surgery group was lower than the normative data $(n=78, P<0.05)$. Compared with the normative data, the $\mathrm{P}$ dimension for the relapse group was higher $(P<0.05)$, and the $\mathrm{L}$ dimension for the relapse group was lower $(P<0.05)$. The non-relapse group showed no significant differences compared with the normative data in all the dimensions of the EPQ. The $\mathrm{N}$ and $\mathrm{P}$ dimensions for the
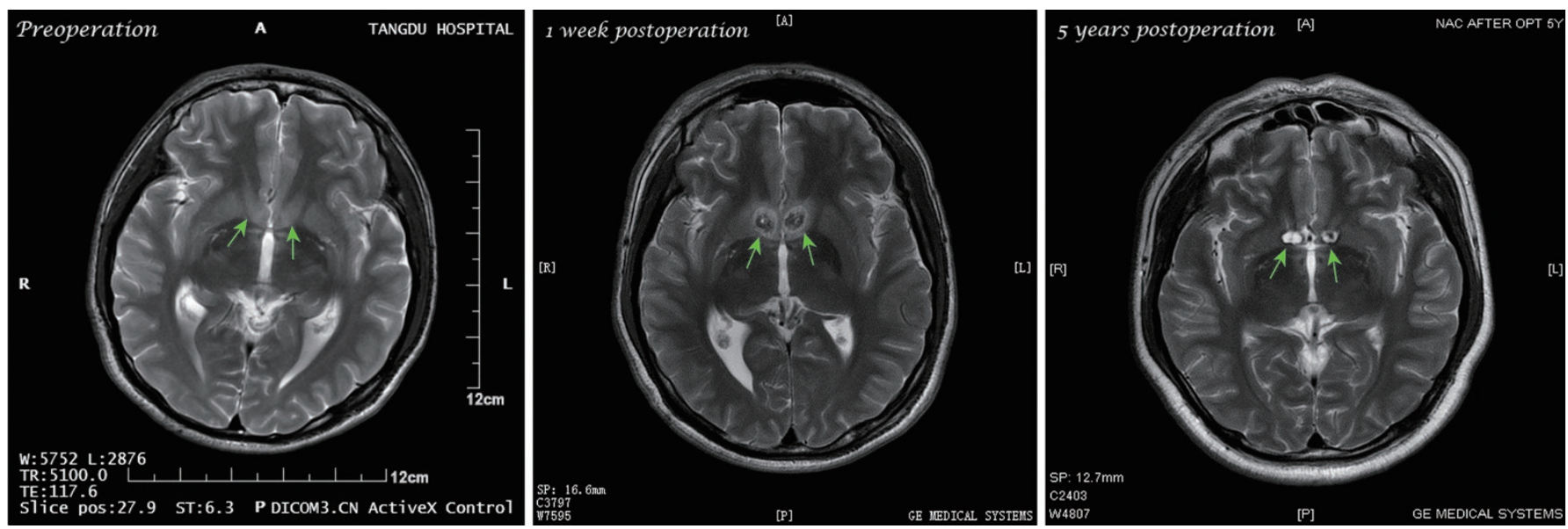

Figure 1. The exial view MRI of the surgery opiates-dependent patients. The place marked by the arrow is the proximal NAc.
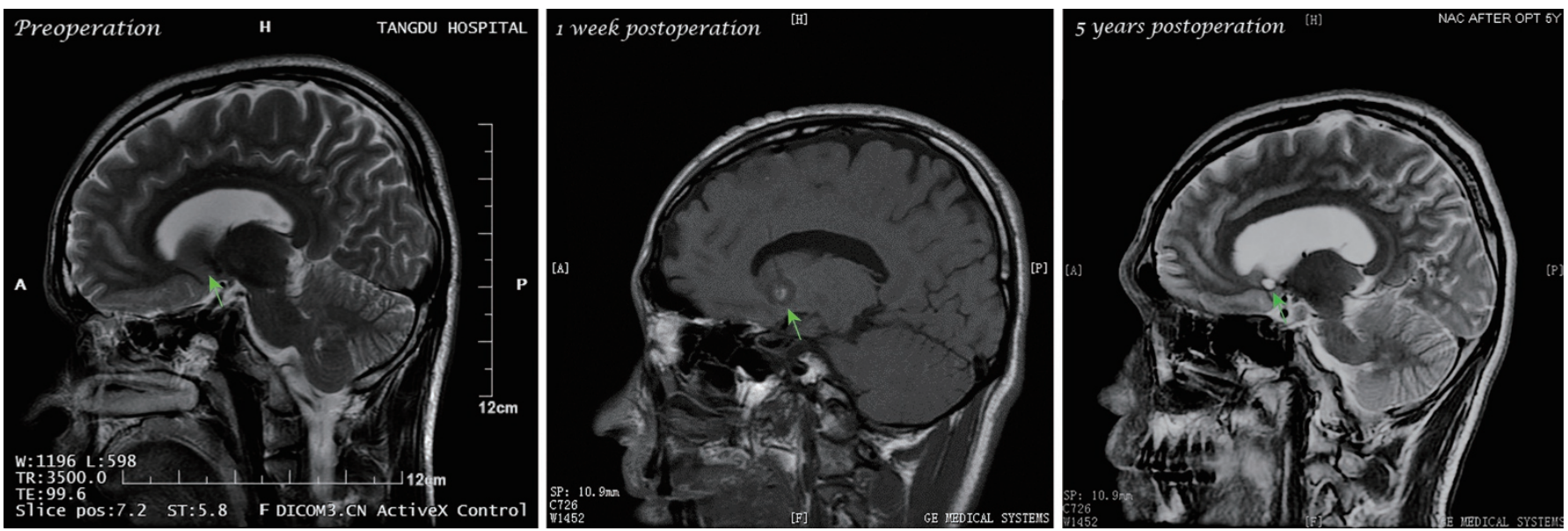

Figure 2. The sagittal view MRI of the surgery opiates-dependent patients. The place marked by the arrow is the proximal NAc.

Table 2. Differences of EPQ dimensions for the groups.

\begin{tabular}{|c|c|c|c|c|c|c|}
\hline $\begin{array}{l}\text { Dimen- } \\
\text { sions }\end{array}$ & $\begin{array}{l}\text { Chinese normative } \\
\qquad(n=1388)\end{array}$ & $\begin{array}{l}\text { Non-surgery group } \\
\quad(n=72)\end{array}$ & $\begin{array}{l}\text { Surgery group } \\
\qquad(n=72)\end{array}$ & $\begin{array}{l}\text { Surgery group } \\
\qquad(n=78)\end{array}$ & $\begin{array}{l}\text { Non-relapse group } \\
\qquad(n=48)\end{array}$ & $\begin{array}{l}\text { Relapse group } \\
\quad(n=30)\end{array}$ \\
\hline P & $5.96 \pm 2.84$ & $8.85 \pm 3.03^{h}$ & $7.10 \pm 3.57^{b}$ & $6.96 \pm 3.64$ & $6.21 \pm 3.33^{e}$ & $8.17 \pm 3.86^{h}$ \\
\hline E & $10.63 \pm 4.44$ & $10.53 \pm 3.51$ & $10.40 \pm 5.44$ & $10.48 \pm 5.26$ & $10.31 \pm 5.34$ & $10.77 \pm 5.20$ \\
\hline $\mathrm{N}$ & $12.17 \pm 3.17$ & $16.19 \pm 4.63^{h}$ & $12.21 \pm 5.04^{b}$ & $12.12 \pm 5.20$ & $11.58 \pm 5.55$ & $12.97 \pm 4.54^{b}$ \\
\hline L & $11.26 \pm 4.26$ & $9.13 \pm 3.58^{h}$ & $9.47 \pm 4.46^{h}$ & $9.55 \pm 4.50^{h}$ & $10.16 \pm 4.64$ & $8.57 \pm 4.16^{h}$ \\
\hline
\end{tabular}

${ }^{\mathrm{b}} P<0.05$ vs non-surgery group; ${ }^{\mathrm{e}} \mathrm{P}<0.05$ vs the relapsers; ${ }^{\mathrm{h}} \mathrm{P}<0.05$ vs Chinese normative. 
surgery group $(n=72)$ and the non-relapse group were lower $(P<0.05)$ than those for the non-surgery group. The $\mathrm{N}$ dimension for the relapse group was lower than for the non-surgery group $(P<0.05)$. The $\mathrm{P}$ dimension for the non-relapse group was lower than that for the relapse group $(P<0.05)$.

\section{Differences in functional health (SF-36)}

As shown in Table 3, there were no significant differences for the RE dimension between the surgery group and the non-surgery group, whereas the other 7 dimensions of the SF-36 were more favorable for the surgery group $(P<0.05)$. The PF and BP dimensions for the relapse group were higher than those of the non-surgery group $(P<0.05)$. Compared with the relapse group, the PF dimension for the non-relapse group was not significantly different, whereas the other seven dimensions of the SF-36 were more favorable for the nonrelapse group $(P<0.05)$.

\section{Correlations between personality or functional health and patients with or without surgery or relapse}

As shown in Table 4, with or without surgery was negatively correlated with the $\mathrm{P}$ and $\mathrm{N}$ dimensions $(P<0.05)$; the $\mathrm{P}$ and $\mathrm{N}$ dimension scores were lower for the surgery group. With or without surgery was not correlated with RE but was positively correlated $(P<0.05)$ with the other 7 dimensions of the SF-36. The functional health of the surgery group was better than that of the non-surgery group. With or without relapse was negatively correlated with the $\mathrm{P}$ and $\mathrm{N}$ dimensions $(P<0.05)$; the $\mathrm{P}$ and $\mathrm{N}$ scores were higher for the relapse group. The non-relapse groups were not correlated with the RE and GH but were positively correlated with the other 6 dimensions of the SF-36 $(P<0.05)$. The functional health of the non-relapse group was better than that of the relapse group.

\section{Discussion}

All the participants within the surgery group were patients who had received bilateral stereotactic NAc lesions 5 to 8 years prior to this study. The non-relapse rate was $61.5 \%$ (minimum) at 5 years after the surgery. In addition, the functional health of the surgery group was significantly better on all of the SF-36 dimensions except the RE. The results indicate
Table 4. Correlations between surgery/relapse and personality/health functioning (Spearman rank correlation). ${ }^{b} P<0.05,{ }^{\circ} P<0.01$.

\begin{tabular}{ccc}
\hline Items & $\begin{array}{c}\text { Non-surgery=1 } \\
\text { Surgery=2 } \\
(n=150)\end{array}$ & $\begin{array}{c}\text { Non-relapse=1 } \\
\text { Relapse }=2 \\
(n=78)\end{array}$ \\
\hline E & 0.012 & 0.019 \\
P & $-0.268^{c}$ & $-0.188^{\mathrm{b}}$ \\
N & $-0.390^{c}$ & $-0.341^{\mathrm{c}}$ \\
L & 0.042 & -0.008 \\
PF & $0.445^{\mathrm{c}}$ & $0.378^{\mathrm{c}}$ \\
RP & $0.335^{\mathrm{c}}$ & $0.257^{\mathrm{c}}$ \\
BP & $0.475^{\mathrm{c}}$ & $0.386^{\mathrm{c}}$ \\
GH & $0.201^{\mathrm{c}}$ & 0.119 \\
VT & $0.269^{\mathrm{c}}$ & $0.195^{\mathrm{b}}$ \\
SF & $0.255^{\mathrm{c}}$ & $0.168^{\mathrm{b}}$ \\
RE & 0.133 & 0.039 \\
MH & $0.279^{\mathrm{c}}$ & $0.202^{\mathrm{b}}$ \\
\hline
\end{tabular}

that the bilateral stereotactic NAc lesions were associated with a relapse rate of only $38.5 \%$ for the opioid addiction patients and improved the functional health of both non-relapse and relapse patients.

The results showed that only the L dimension was significantly lower in the surgery group relative to the Chinese normative data. Notably, the personalities of the non-relapse patients within the surgery group were not different from those of the Chinese normative data. However, the P dimension was significantly higher and the L dimension was significantly lower for the relapse group compared to the Chinese normative data. The difference in the L dimension for the surgery group was probably attributable to the relapse patients. The personalities of the relapse patients showed a higher tendency toward psychoticism and a lower tendency to lie.

Unfortunately, this study lacked preoperative data for the EPQ. As a feasible means of redress, a matched non-surgery group was included in this study. It has been reported that opiate addicts have specific personality characteristics, including an unstable personality with a tendency to be sensitive, suspicious, anxious, changeable, curious, impulsive, aggres-

Table 3. Average values and differences for the health survey questionnaire (SF-36).

\begin{tabular}{|c|c|c|c|c|c|c|c|c|}
\hline Items & $\begin{array}{l}\text { Non-surgery group } \\
\qquad(n=72)\end{array}$ & $\begin{array}{l}\text { Surgery group } \\
\qquad(n=72)\end{array}$ & $t$ & $P$ & $\begin{array}{l}\text { Non-relapse group } \\
\qquad(n=48)\end{array}$ & $\begin{array}{l}\text { Relapse group } \\
\qquad(n=30)\end{array}$ & $t$ & $P$ \\
\hline PF & $63.61 \pm 27.38$ & $87.12 \pm 13.08$ & 6.62 & 0.000 & $89.17 \pm 12.26$ & $83.83 \pm 13.88^{b}$ & 1.78 & 0.080 \\
\hline $\mathrm{RP}$ & $45.49 \pm 39.43$ & $72.12 \pm 37.79$ & 4.22 & 0.000 & $79.17 \pm 33.55$ & $60.83 \pm 41.88^{\mathrm{e}}$ & 2.13 & 0.036 \\
\hline $\mathrm{BP}$ & $59.32 \pm 23.56$ & $79.23 \pm 16.35$ & 5.97 & 0.000 & $83.08 \pm 12.61$ & $73.07 \pm 19.71^{b}$ & 2.74 & 0.008 \\
\hline $\mathrm{GH}$ & $47.72 \pm 18.84$ & $57.50 \pm 27.14$ & 2.58 & 0.011 & $63.21 \pm 27.23$ & $48.37 \pm 24.78^{\mathrm{e}}$ & 2.42 & 0.018 \\
\hline $\mathrm{RE}$ & $50.46 \pm 41.86$ & $61.97 \pm 40.82$ & 1.70 & 0.091 & $72.92 \pm 37.45$ & $44.44 \pm 40.43^{\mathrm{e}}$ & 3.17 & 0.002 \\
\hline $\mathrm{MH}$ & $54.06 \pm 15.86$ & $65.33 \pm 21.90$ & 3.63 & 0.000 & $69.33 \pm 21.35$ & $58.93 \pm 21.58^{\mathrm{e}}$ & 2.09 & 0.040 \\
\hline
\end{tabular}

${ }^{\mathrm{b}} P<0.05$ vs non-surgery group, ${ }^{\mathrm{e}} P<0.05$ vs non-relapse group. 
sive, poorly self-controlled, hedonistic, excitement-seeking and antisocial ${ }^{[10-13]}$. The results for the non-surgery group were similar to those reported above, with participants having higher $\mathrm{P}$ and $\mathrm{N}$ dimensions and a lower $\mathrm{L}$ dimension than the Chinese normative data. Compared to the non-surgery group, the $\mathrm{P}$ and $\mathrm{L}$ dimensions were notably lower for the surgery group.

The $\mathrm{N}$ dimension was significantly lower for the relapse group compared to the non-surgery group, whereas no differences between these groups were revealed in the other 3 dimensions of the EPQ. All participants in this comparison were opiate addicts. The difference among the groups was that the relapse patients had received bilateral stereotactic NAc lesions at least 5 years previously with a minimum time difference of 5 years (ie, the relapse patients had taken opiates for a minimum of 5 more years than the non-surgery patients). As a result, it is suggested that the difference for the $\mathrm{N}$ dimension may have been due to the surgery and/or the time difference.

When the non-relapse group was compared with the relapse group, the $\mathrm{P}$ dimension of the non-relapse group was significantly lower, while no differences were revealed in the other 3 dimensions of the EPQ. As all participants in this comparison had received the bilateral stereotactic NAc lesions, it is possible that the difference for the P dimension was mainly associated with relapse. In other words, a higher P score or a longer duration of opioid use (minimum 5 years) led to a greater risk of relapse.

The EPQ, developed by Eysenck, is a personality inventory based on the personality theory of physiological psychology ${ }^{[14-16]}$. According to Eysenck, the physiological principle of the E dimension is the excitability level of the cortex. Low excitability levels of the cortex are thought to be associated with extroverted personality traits, whereas high excitability levels of the cortex are associated with introverted personality traits. The ability to form conditioned reflexes was believed to be relative to the $\mathrm{E}$ and $\mathrm{N}$ dimensions. The formation of strong, conditioned reflexes was associated with introverted personality traits and more stable emotions, whereas a weak reflex ability was associated with extroverted personality traits and less stable emotions. The concepts of emotionality and drive, which are influenced by the balance of the function between the sympathetic and parasympathetic nervous systems, are related mainly to the $\mathrm{N}$ dimension and only partly to the $\mathrm{E}$ dimension. If the sympathetic nervous system is dominant, highly unstable emotions prevail. Eysenck thought that the $\mathrm{P}$ dimension, which he added at a later stage, was relative to increased androgen levels ${ }^{[15]}$.

The concepts cited by Eysenck have been explored using laboratory examinations. Research indicates that the vital brain centers of emotional processing include the hypothalamus, septal area, amygdaloid nucleus, hippocampus, limbic cortex, prefrontal cortex and temporal lobes ${ }^{[16]}$.

The NAc neurons are implicated in behaviors that are elicited by reward-predictive sensory cues ${ }^{[4,17,18]}$. The anatomical characteristics and functional associations of the NAc indi- cate that it may play an important role in the development of euphoric feelings and other forms of positive reinforcement. Furthermore, it is possible that the NAc influences the formation of learned conditioned reflexes, the functioning of the sympathetic and parasympathetic nervous systems, and the secretion of androgen.

If the difference in the $\mathrm{N}$ dimension between the relapse group and the non-surgery group was caused by the bilateral NAc lesions, this indicates that the NAc might contribute to the formation of learned conditioned reflexes and the functional harmonization of the sympathetic and parasympathetic nervous systems. However, this difference in the $\mathrm{N}$ dimension might also be attributable to the additional 5 years of drug abuse in the non-surgery group compared with the relapse group. The difference in the $\mathrm{P}$ dimension between the relapse and non-relapse groups might be associated with the personality factors of the participants themselves. The participants with a higher $\mathrm{P}$ score tended to relapse more easily, but this effect on personality may be the result of drug use. According to Eysenck's theory, one could interpret the results in terms of androgen secretion: high levels of androgen secretion might be associated with the risk of relapse, or the frequency/duration of drug taking may facilitate androgen secretion. The lack of a significant difference for the E dimension between the surgery group and the Chinese normative data, the surgery and nonsurgery groups, the non-surgery and relapse groups, and the non-relapse and relapse groups indicates that the surgery did not influence the E dimension. This result suggests that NAc lesions have little influence on cortical excitability.

Overall, the results show a reduction in the $\mathrm{P}$ and $\mathrm{N}$ dimensions for the opioid addicts, which may be attributable to the bilateral NAc lesions in the surgery group; however, the influence of other factors cannot be excluded.

Although the study design limits the conclusions that can be drawn, the phenomena we observed highlight a number of avenues for future research. For instance, future studies could address how the personalities of opiate addicts are affected by opioid dosage changes or prolonged drug abstinence. Questions remain regarding the possibility that a lesion to a specific region of the NAc may improve the ability to form learned conditioned reflexes. Further investigation is necessary to determine if there is a change in the balance between sympathetic and parasympathetic nervous system activity following NAc lesions and whether NAc lesions affect the secretion of androgen. Although the NAc lesion operation used to treat drug addiction was discontinued because of ethical concerns, our investigation highlights a number of important factors associated with the surgery. Subsequent research will focus on long-term observations of the postoperative patients to reevaluate the operation.

\section{Acknowledgements}

This work was supported by a grant from the Project of Reevaluation to Clinical Therapy of Existing Relapse Prevention Therapy under the National "Eleventh Five-year" Technology Supporting Plan (№ 2007BA107B03). 


\section{Author contribution}

Guo-dong GAO and Xin WANG were responsible for the conception and design of the study; Hai-kang ZHAO and Chong-wang CHANG contributed to the data acquisition; Ning GENG was responsible for data analysis, the interpretation of findings and the drafting of the manuscript; other authors participated in collecting data; and all authors critically reviewed the content and approved the final version for publication.

\section{References}

1 Wang XL, He SM, Heng $\sqcup$, Li WX, Liang QC, Li J, et al. Analysis on follow-up results of bilateral nucleus accumbens ablation for ablating drug dependence. Chin J Neurosurg 2005; 21: 579-84.

2 Flynn PM, Joe GW, Broome KM, Simpson DD, Brown BS. Recovery from opioid addiction in DATOS. J Subst Abuse Treat 2003; 25: 177 86.

3 Volkow ND, Fowler JS, Wang GJ. The addicted human brain: insights from imaging studies. J Clin Invest 2003; 111: 1444-51.

4 Nicola SM. The nucleus accumbens as part of a basal ganglia action selection circuit. Psychopharmacology (Berl) 2007; 191: 521-50.

5 Lecca D, Piras G, Driscoll P, Giorgi O, Corda MG. A differential activation of dopamine output in the shell and core of the nucleus accumbens is associated with the motor responses to addictive drugs: a brain dialysis study in Roman high- and low-avoidance rats. Neuropharmacology 2004; 46: 688-99.

6 Cardinal RN, Howes NJ. Effects of lesions of the nucleus accumbens core on choice between small certain rewards and large uncertain rewards in rats. BMC Neurosci 2005; 6: 37.

7 Gao GD, Wang XL, He SM, Li WX, Wang QF, Liang QC, et al. Clinical study for alleviating opiate drug psychological dependence by a method of ablating the nucleus accumbens with stereotactic surgery.
Stereotact Funct Neurosurg 2003; 81: 96-104.

8 He F, Guan H, Zhao ZJ, Miao XF, Zhou Q, Li LH, et al. Evaluation of short-term psychological functions in opiate addicts after ablating the nucleus accumbens via stereotactic surgery. Stereotact Funct Neurosurg 2008; 86: 320-9.

9 Gong YX. Eysenck personality questionnaire (Chinese revision). Changsha. Hunan Map Press; 1984. p45.

10 Wills TA, Windle M, Cleary SD. Temperament and novelty seeking in adolescent substance use: convergence of dimensions of temperament with constructs from Cloninger's theory. J Pers Soc Psychol 1998; 74: 387-406.

11 Sarramon C, Verdoux H, Schmitt L, Bourgeois M. Addiction and personality traits: sensation seeking, anhedonia, impulsivity. Encephale 1999; 25: 569-75.

12 Franques $\mathrm{P}$, Auriacombe M, Tignol J. Addiction and personality. Encephale 2000; 26: 68-78.

13 Kozlov AA, Rokhlina ML. “Addictive" personality. Zh Nevrol Psikhiatr Im S S Korsakova 2000; 100: 23-7.

14 von Gunten A, Pocnet C, Rossier J. The impact of personality characteristics on the clinical expression in neurodegenerative disorders - A review. Brain Res Bull 2009; 80: 179-91.

15 Eysenck HJ. Biological dimensions of personality. In: LA Pervin (Ed), Handbook of personality: Theory and research. New York: Guilford 1990; 244-76.

16 Shen Z, Lin SZ. Physiological psychology. Beijing: Peking University Press 1993: 233.

17 Cardinal RN, Parkinson JA, Hall J, Everitt BJ. Emotion and motivation: the role of the amygdala, ventral striatum, and prefrontal cortex. Neurosci Biobehav Rev 2002; 26: 321-52.

18 Humphries MD, Prescott TJ. The ventral basal ganglia, a selection mechanism at the crossroads of space, strategy, and reward. Prog Neurobiol 2010; 90: 385-417. 